\title{
A Study on the Influence of Human Cultural Environment on Literary Creation from the Perspective of Eco-criticism
}

\author{
$\mathrm{Li} \mathrm{Hou}^{1}$, Jianjun Kang ${ }^{1,2, *}$ and Yongli $\mathrm{Xu}^{1}$ \\ 1 "Belt and Road” Region Non-common Languages Studies Centre of Liaocheng University, Liaocheng, Shandong \\ 252059, China \\ ${ }^{2}$ Institute of Literature of Jiangxi Academy of Social Sciences, Nanchang, Jiangxi 330077, China \\ *Corresponding author.Email: akanghao@vip.163.com
}

\begin{abstract}
The geographical environment can have a great influence on the cultural and psychological structure of literary writers, and thus on their creations in practice. The manifestations or carriers of these influences indirectly bring time and spaced close together. The study of the influence of the human cultural environment on literary creation from the perspective of eco-criticism reveals that literature is in many cases a projection of local culture in literary works, which always contains the mental history of the writer's growth and psychological development. In the creation of works, writers often integrate the ecological concept of coexistence between human beings and the environment with their thoughts on individual identity, and put their rich imagination into different regional literary creations; while these works awaken human beings to regain their sense of place and homeland, writers also eventually heal their trauma caused by the loss of their homeland and realize the construction of their own identity, thus completing the writing of place and space. Writing about place and space. From the perspective of eco-criticism, human culture and geography provide the basic material basis for literary creation, which in turn provides an aesthetic reference for creation; therefore, eulogizing nature is a tradition and an important theme for excellent works. In the field of ecocriticism, human civilization and geography interact well. The external environment profoundly influences and shapes the cultural character of creators, and the external environment also reminds writers to protect the ecological environment and care for our natural world in their works through external perception.
\end{abstract}

Keywords: Eco-criticism, human culture, geographical environment, literary creation, interactive

relationship

\section{INTRODUCTION}

Literary creation is an important process of self-exploration and outward expression for writers, who use the time and space in which they live to complete the construction of ideas and expression of output, so that their own life emotions and life experiences correspond to the natural and human environment of the region, thus completing the creation of a characteristic literary style. The human cultural environment provides the initial material for the material experience and external perception of the creator and further contributes to the establishment of the aesthetic consciousness of his creative style.

The ecological environment and human culture have contributed to the creation of literature, and the works have constantly given new symbols to the regional environment to enrich its image, and the two have influenced and promoted each other.

\section{HUMAN CULTURE AND ENVIRONMENT PROVIDE MATERIAL BASIS AND AESTHETIC REFERENCE FOR LITERARY CREATION IN THE PERSPECTIVE OF ECO-CRITICISM}

In the process of long-term historical development, human beings have formed an inseparable link with culture and environment, and human beings have continuously explored and rubbed together in the process of getting along with nature, and then formed a way of life and specific regional culture adapted to the environment, and different human cultures and environments have shaped the material basis of differences and created the external support for regional culture within a certain range in the process of continuous human practice to become their potential Aesthetic orientation. The process of mutual influence and promotion between the two in the eco- 
critical perspective is the process of constructing their dynamic balance.

\subsection{Excellent Literary Works Reveal the Relationship between People and Land and Balance the Relationship between Eco-critical Environment and Literary Creation}

According to Engels' view of literature and art, literary creation relies on the overall social environment of politics, economy, and culture under the long-term influence of human culture and environment, which has a strong twoway effect on the formation and shaping of literary style. Based on the eco-critical perspective, the influence of the human cultural environment on literary creation can be explored and interpreted, to clearly explain the linkage between the two and the development situation, and thus promote the systematic construction of a dynamic balance of literary creation under the humanistic human cultural environment[1].

The different topographical conditions of each region have created many different regional human cultures and environments, and the different landscape features and climate types determine the lifestyles and behavioral habits of regional people, and thus the regional cultures are maturely constructed. In this context, the regional interval further increases the cultural differences between regions and triggers the creation of regional literary creations, such as different poetry genres and novelist factions, which are typical representatives of them. Therefore, human culture and environment naturally become the fundamental background portrait and symbol of meaning for literary creation.

\subsection{Literature Projects and Focuses on the Environment, Feeds Back and Records the World}

Literature and geography interact with each other, literature is people's spiritual mapping of the material world, and geography is the embodiment of spatial forms in form; the combination of the two will give a new definition to measure the world. The countryside and the city are geographically two opposite or even non-intersecting concepts, the countryside is mainly based on natural geography, while the city has strong humanistic geography; but it is because of this difference in spatial geography that the diversity of literary themes is nurtured, in other words, space is historical, and the history of spatial forms often overlaps with the history of narrative forms, and literary geography also provides a very important way to study texts. The history of spatial forms often overlaps with the history of narrative forms, and literary geography provides a very important way of studying texts.

As geographic phenomena change, material carriers change, and the horizontal time axis evolves, literature and geography combine to produce a new perception and insight into society and culture based on regional cultural characteristics; in this way, they try to explain and change the world through spatial relations, and place life in social and spatial relations to develop continuously in the social structure with a spatial perspective.

The Call of the Wild is a representative work of a modern American realist writer Jack London, and it is also the most important piece of naturalistic literature in the 19th to 20th centuries. Although the author takes a $\operatorname{dog}$ as the main character, he reveals the story of the human world. The novel is set in a period when the United States in the process of shifting from an agrarian society to an industrial society. Behind the rapid development of the capitalist economy is the endless plunder of nature by people, the author exposes the destruction of nature by humans through Buck's perspective, fully reflecting his critique of anthropocentric ecological destruction. From the perspective of Eco-criticism, this paper explores the relationship between Buck and different owners and the author's criticism of the destruction of nature by humans to reveal the ecological crises faced by humans and their causes. And it provides some reference value on how humans can live in harmony with nature.

\subsection{The Work Shapes Many Emotional Places, Which Can be Found in Real Life}

In the introduction to Spatiality, the author represents the sensitivity and complexity of such premises by marking your location on a map and opens by citing the famous opening imagery from Dante's Divine Comedy to point out that our most pressing anxiety is largely embodied in the fear of being lost in space, and in the assumption and uncontrollability of spatial disorientation. Dante recounts that he was lost in a dark forest in a dream, that he met a leopard, a lion, and a she-wolf, and that is lost in the middle of a dark forest in the middle of his life is enough to show how difficult that forest is! This is no less than the visit of death. He did not know exactly how he entered that forest, except that he lost the right way in his drowsiness. Space is mixed with several emotions so that in the question of emotion and space, Dante first gives an emotional element to location, premises, and place.

As an extension of the, You are here logo above, the writer must choose a particular place or a particular story to make the narrative map rich in meaningful details that can be experienced and perceived by the reader. This is the same requirement for true mapmakers - narrators and writers. The mapmaker decides to convey different meanings to the map reader through the functions of the map, while the narrator, the writer, writes creatively to integrate and reorganize the story and present it to the reader. A map that is only provided for the use of car drivers is undoubtedly a failure because the traveler cannot learn more details of the journey from it, while the narrator, the writer, should convey plot and story content to the reader in the text, as in the case of Great Tang Records on the Western Regions 
and Red Star Over China, where there is a vine style road map of the journey and several fascinating stories can be knotted up on the vine. These plots, all of which are designed to increase readability and emotionality, in turn, give places an emotional identity[2].

Eco-criticism refers to the long-term mapping of environmental and ecological problems in literary works and aims to reveal the ecological thoughts contained in literary works or cultural phenomena and the ideological and cultural roots of the ecological crisis reflected. As a tendency of literary and cultural criticism, Eco-criticism was formed in the United States in the mid-1970s and then developed in many countries around the world. There are many controversies in the definition of Eco-criticism, among which scholars are the best accepted is the definition of Cheryl Grotfilty, the main advocate and initiator of American Eco-criticism, "Eco-criticism is a criticism that explores the relationship between literature and the natural environment" .

\section{HUMAN CULTURE AND ENVIRONMENT IN ECO-CRITICAL PERSPECTIVE SHAPE THE CULTURAL CHARACTER OF THE CREATOR AND THE EXTERNAL PERCEPTION OF THE WORLD}

Human culture and environment provide nourishment for the life and livelihood of regional people, and at the same time, human beings transform them through practical activities. The influence of the human cultural environment on people and the smooth construction of human feedback in the ecocritical perspective is the demonstration of dynamic balance. Human culture and environment provide living space and material foundation for human beings, and in the process of continuous development, they become the soil for shaping the temperament and customs of people in the region, and they create and portray the latter in the process of communication and interaction with human beings. The differences in human culture and environment have a profound impact on the internal characters and things and result in differences in inner cultivation and aesthetic style. As a typical representative of the regional cultural image, a writer's cultural character and aesthetic perception are the concentrated expressions of the regional environment. The differences in human cultural environments between countries have created great differences in folk cultures and lifestyles among different regions and ethnic groups, and the resulting differences in food, clothing, architecture, and other elements are particularly significant.

Chinese people have long times under the shine of agricultural civilization, which has led to the formation of a peaceful, diligent, and calm national culture, thus forming a calm and docile character, with homesickness and sadness becoming the eternal theme of literary creation. At the same time, the fading and depressing scenery in autumn and winter is very likely to trigger bleak and sad emotions, thus the literary creations in the grassland region often contain a sense of majestic, while the people in the coastal region have a strong adventurous spirit due to their frequent contact with the mysterious and unpredictable sea. Different human cultural environments bring different perspectives and emotional tones to writers, which in turn affect the style of their works.

\subsection{Works Should Reflect the World While Returning to Nature and Landing on the Objective Laws of Nature}

How does literature give us a sense of spatiality? In Spatiality, the writer portrays literature as a form of mapping. When the spiritual world is barren, we have a sense of anxiety and restlessness, and we ask ourselves Plato's ultimate three questions: "Who am I? Where do I come from? Where am I going?" At this point, literature serves the function of drawing a map, presenting readers with a picture of a certain place, allowing them to enter the space of their imagination, and providing various reference points in their spiritual world so that readers can familiarize themselves with and understand their own lives based on the reference points.

Reading is not to possess, not to remember, but to give we an extra light in the darkness, to give ourselves a reference of space. There are more lights in the distance so that we can have a sense of space in the world, and the world will show itself to us. We arrive at places we have never been before and encounter things we have never encountered before without panicking. Although we have low selfesteem, care about the eyes of others, and fear death, we have also been told long ago that life and death have a destiny and need to embrace it[3]. When we encounter all kinds of sorrows and joys, we know that it is an unusual event that happens in this human history. When our spiritual world is enriched, we do not feel a strong sense of loss, but rather certain confidence to live actively in the world. In a metaphorical sense, a writer's writing is a "literary mapping," a drawing, projection, and reproduction of the world we live in, and writing a literary work for others to read is to help people find a sense of space in the spiritual world.

Therefore, human culture and environment in the ecocritical perspective bring indelible historical traces to the literary creation of creators, fundamentally build the material basis and aesthetic tendency of literary creation and lead the regional culture and the overall style of literary works to achieve benign shaping. 


\subsection{The Writer Completes the Reflection on Geographic Space in the Philosophical Sense in Speculative Thinking}

The space in modern philosophy is beyond experiencing space, which also provides a breakthrough idea for creative writing. That is how to build the space for storytelling and carry out scientific planning and layout in the space during the writing process, so that each secondary space, which is isolated separately, accommodates the complete storytelling. In the theoretical framework of creative writing, space is a very important concept, even more, important than time. A neat and orderly space can accommodate more levels of storytelling and facilitate the unfolding of writing.

What concerns many human geographers, literary scholars and philosophers is the internal space about the field of the mind and imaginative associations that are inward, literary, and artistic, and through this inward reflection, holistic perception of the external space and the external world is mobilized. Spatiality argues that Descartes adhered to Euclid's concept of space, which he considered to be indivisible from the objects within it. Whereas Aristotle took objects to mean anything with mass and dimension, for Descartes the fundamental characteristic that all objects possess is the extension of space. So, what we think of as space is what Descartes sees as the "extension of an object" . A bottle full of water is still full of air, even if it is empty. A bottle full of water and empty is full in the eyes of Descartes. In a top-down sense, then, there is no space, no empty matter, because it will always be full of something.

In Baudelaire's world, everything in the world is like a vast mirror; or like a kaleidoscope with the consciousness that reacts to every human action in the same way or in exactly the opposite way, thus creating the diversity of life and the shimmering grace and beauty of all elements of life. The "I" in Baudelaire's writing is introspective, inescapable from desire, and free from transcendence, and he expresses and explains it every moment with images more vivid than life itself, which is always unstable and fleeting. This creative writing about life and self is itself one of the ultimate missions of writing.

\subsection{Geographical Space Plays an Important Role in the Writer's Creation in a Three- dimensional Way}

Space overrides time in many cases. As time passes and changes, space changes with it. But arts like inscriptions and paintings will eventually regulate into space in terms of value. The emergence of new fields causes the irreversibility of time to break down, and everything gets rearranged. Although it is talking about geographical literature, it also involves historical aspects and speaks about the perception of the East in European countries, containing a certain mythical, hypothetical meaning.
During the medieval period in Europe, it was common to believe that there were still gods and demons in the world, and their definition of such space was an imaginary one. However, Marx thought that space should belong to beautiful socialism, while capitalism is full of certain stench, he did not agree to define space as the scope of capitalism, he thought it belonged to the definition of space in a subjective sense. Also, during the colonial period, the exploitation of India by countries like Britain and America was their subjective sense of wanting to regulate the spatial scope of India to their national scope.

Modernism has a structure that makes people's interpretation of some phenomena limited to a framework, however, postmodernism emerged with a more open-ended structure that allows people to interpret things in a more multifaceted way, with an open mind and an open perception. Illustrations have a very important and intuitive role in interpreting some things. Many things in terms of language and literary definitions can be described graphically to make the concept more impressive. Thus, the object of study can be made to feel palpable, similar to spatiality, which no longer exists in three dimensions in the mind, but is still presented to the reader in two dimensions.

\section{IN THE FIELD OF ECO-CRITICISM, WRITERS TRANSFORM THE DIFFERENT CULTURES IN DIFFERENT KINDS OF HUMAN CULTURAL ENVIRONMENTS INTO THEIR AESTHETIC ORIENTATION THROUGH
LITERARY CREATION}

In the Field of Eco-criticism, Writers Transform the Different Cultures in Different Kinds of Human Cultural Environments into Their Aesthetic Orientation through Literary Creation.

The individual creator and the human cultural environment under the ecocritical perspective complete a good construction of dynamic balance between them through mutual communication. Individuals depend on human culture and environment for their growth and development, and the influence of human culture and environment on local communities not only shapes their production and lifestyle, but also has a great impact on their thinking patterns, value orientations, and aesthetic consciousness.[4] Literary creation is not a pavilion in the air, the creative process needs to rely on the reality of the material world and the ideological foundation, to complete the quality of creation close to people's minds and spirits. Therefore, the writer's description of the background environment and living conditions in the process of literary creation must be closely related to its human cultural environment, and the construction of imagery and atmosphere under the influence of the human cultural environment is inseparable from its inherent living environment, which makes literary works full of regional cultural colors. 
At the same time, the inherent material properties of human culture and environment provide writers with continuous creative inspiration, and constantly stimulate writers' emotional and expressive passions, so that through writers' selection and internalization, they become the witnesses and bearers of their individual development and ideological changes, and finally establish a perfect personal academic trajectory and spiritual world, and complete the exploration and integration of writers' literary creation influence on a macro level.

Emerson's nature thought considers nature as the incarnation of God, which is consistent with today's ecocritical ethics. Nature, being part of God's creation,

"For God, everything in nature has intrinsic value, and God is concerned with everything in nature, animate and inanimate, human and nonhuman, animals and plants” , and from this premise, with eco-critical and theological overtones, we can infer such from this premise, with ecocritical and theological overtones, we can infer the ecocritical ethical norm that irresponsibly destroying our whole and interconnected environment is a crime against the good world created by God. Emerson's eco-critical nature thinking is an important guide for the church's involvement in the environmental movement and its advocacy of "green religion".

\subsection{Eco-critical Vision of the Writer's Pictorial Depiction of the World Shows a Better Nature}

Literary mapping is not only a study of literary space but also to a certain extent a study of writing techniques, which helps writers push the limits, brainstorm, and create new writing modes to create a more realistic literary world. Literary mapping combines the two dimensions of time and space, macro and micro, and to some extent can be seen as a writer's mapping and construction of literary space from God's perspective. However, both narrative writers and science fiction writers cannot completely escape the influence of the real space on their creations, which can be found in the real world. Pure fiction or imagination will lose the basis of reality and will not resonate with readers.

Writing itself may be seen as a form of drawing or cartography, a literary writer constructs a literary space through literary drawing, then the reader's reading behavior can be seen as a secondary drawing. Today's fast-paced life gradually makes people lose themselves in different but intertwined realities, and gradually lose their true nature. Different readers are in different life situations, different personal life experiences, and many other factors that will affect the appearance of the reshaped space. The literary space that readers get varies, but to some extent, they can all be regarded as a utopia or a paradise, which can help people forget about the various flavors of life for a short time, get spiritual solace, and get the motivation to move on in the real world.

The theoretical study of literary creation based on human culture and environment should be based on the perspective of eco-criticism, scientific understanding of the usefulness and value of the relevant elements in the creation process, and then build a logical framework at the overall level to provide a theoretical basis for the subsequent improvement of the quality of literary works and the dissemination of national culture as a whole, and ultimately realize the leadership of Chinese literary works in the world.

Knowledge of spatial structures such as shape, size, orientation, location, dimensionality, and interrelationships of spatial targets forms the cognitive map of our living environment and influences our spatial decisions and behaviors. The actual distance is sometimes different from the cognitive distance, and the map obtained by detailed study of the concept of cognitive distance and precise measurement is different from the cognitive map of the region, mainly in terms of measurement accuracy. A cognitive map can be understood as people's perception of the real world, a large amount of knowledge about the spatial structure of the environment that a person has in his or her mind. People construct and develop cognitive maps by recording information from perceptions, natural language, and derivations. The main body of the presentations in this group is three aspects of spatial experience out of home, creative space and the transcendence of writing, and spatial criticism, and the postmodernity of spatial theory.

\subsection{A Deeper Exploration of Eco-critical Theory Can Enable Readers to Better Understand the Meaning and Value of Geographic Space}

Here or there is the key to understanding the spatial thrust of poetics. Here or there, starting from utopia, is the key to understanding space, to understanding writing. The book Spatiality says that on English maps, or even on the guide maps we see every day when we enter tourist areas, the first thing that comes to mind is the You are here sign, marking: where you are, you are here. The Spatiality draws on the language of maps to emphasize the importance of maps and the importance of getting one's bearings in the map system, and in doing so, it draws out the most searing context of our time and culture: a general sense of spatial disorientation and spatial anxiety.

The globalization of the world has constantly renewed the connotation of poetic space, which is increasingly transformed from an economic form to an ideological concept, and space has undoubtedly been given the added value of politics, conflict, and struggle rather than a simple geographical place. Space is at the same time a contested thing, offering a variety of possibilities for reconstructing human narrative space and living space. In this context of the times, literary spatial criticism often reveals the meaning and impact of social change and constructs ideal utopias through the construction, revision, and transformation of space in texts, which from this 
perspective, is a key to our understanding of the poetic spatial thrust of literary works.

Space is historical, and the history of spatial forms often overlaps with the history of narrative forms. In spatiality, Ecko's anecdotes also embody the important relationship between fictional and real space. The literary mapping of parts of Paris created by Eco through language and imagination becomes a text for readers to interpret and analyze. Readers tend to associate imaginary places with places they might encounter in the city, thus creating a strong empathy for the characters in the literature, whose thoughts and actions also have an impact on the readers' perceptions and ideas. Is the real space in foreign literature a superimposition of the unreal space or a reflection of the real society? For example, in Moby Dick, Herman Melville describes in detail the process of studying the map, making a route, and recording known information to describe the scene of Ahab's pursuit of Moby Dick, which is closely related to the writer's life experience.[5] The Pacific Ocean provided the real space for Melville's literary drawings. Both Moby Dick and the Polynesian Trilogy seem to describe the writer's adventures during his voyages, but in fact, they are based on the real space of the Pacific Ocean. The main theme of this panel is that the writer's work is based on the real space of the Pacific Ocean. The main themes of this panel are the construction of the image of the other and the mental map, and the criticism and reflection of literature and geography as two disciplines in the combined zone.

\subsection{Eulogizing Nature is the Tradition of Excellent Works, and Only Works that Place the Activity Scene in Nature are Profoundly Meaningful}

Celebrating nature is a tradition of great works. Writers continue to draw the nourishment of life from nature, inspiring generations of readers. In their works, writers have reflected on industrial civilization, criticized the excessive expansion of human desires and the cruel plundering of nature, and yearned for nature, enjoying its tranquility and peace. As human society continues to develop, ignorant and arrogant humans try to conquer and dominate nature.

The relationship between man and nature can be divided into two categories: one is the physical and chemical external relationship; the other is the " emotional connection" between the human mind and nature, which is not only an innate emotional connection but also a product of human and social evolution. It is often referred to as the "ecological subconscious". Writers complete their works based on "emotional connection" , which to a certain extent reflects the writers' instinctive ecological conscience, which is also lacking in today's society.[6] As society develops and progresses, people gradually forget their love, reverence, and worship for nature. The study of eco-ethics can awaken people's ecological conscience and stimulate their deep emotions. Reading the writers' works can, on the one hand, awaken the profound natural emotions in people's memory, and on the other hand, strengthen human reflection on nature so that human emotions toward nature will never be separated. Only by awakening the profound ecological conscience of human beings can we move toward an eternal state of harmony in peaceful coexistence with the environment.

Many eco-critical works convey to us that nature is mysteriously destructive and that it is time for us to change the image of our rulers and respect nature. When we realize that we are products of nature, just a small part of everything in the world, we should get closer to nature, integrate into it, carefully appreciate it and enjoy its infinite charms: we can freely absorb nutrients from its surroundings and gain physical and mental freedom and comfort[7].

\section{CONCLUSION}

The space in the work can be seen as a reconstruction of literature between territory, place, and language, which is the literary space and poetic space that creative writing can reconstruct, and thus become an essential part of the composition of this complex and complicated world. The linguistic landscape of the work also reveals how the places and landscapes in the work are rendered meaningful. Eco-criticism advocates liberating nature and returning to nature, returning human nature to a natural state, and realizing the benign interaction between spiritual ecology and natural ecology. Eco-criticism criticizes a humancentered value and life production method, trying to build a natural, ecological, and sustainable production and lifestyle with the purpose of ecological overall interests, a new type of relationship between humans and nature. Eco-criticism is a new type of criticism with a strong sense of ecological responsibility. It aims to establish the independent value and significance of "nature" itself. It regards "nature" as a basic element of cultural research and literature and art, and can indirectly inspire the reader's ecological awareness and promotion of ecological and environmental protection actions[8].

In their works, the writers often combine the ecological concept of coexistence between human beings and the environment with the contemplation of individual identity, and combine rich imagination in writing about different places; while such works awaken human beings to regain a sense of place and home, the writers eventually ease the contradiction between ideal and reality, regulate the tension between human society and nature, realize the construction of their own identity, and complete the writing about place and space. Judging from the current theoretical research and practice of Eco-criticism, Eco-criticism has broad and narrow targets. The narrowly defined objects include only those texts directly related to natural ecology. Some scholars call such ecological criticism as ecological literary criticism. In a broad sense, the object of criticism refers to all human cultures including literature and art. The idea of harmony between man and nature, which 
advocates the harmony between man and nature, or the ideology and culture that advocates that man is the controller of nature.

Through the writers' works, we can see how the created world is brought to our senses so that we can indeed experience the spatial environment of the works. This perceptible spatial environment of the literary works focuses on the text itself and the geographical environment, thus serving the dual purpose of interpreting and delving into the text and the real space.

\section{ACKNOWLEDGMENT}

This paper was funded by Identify applicable sponsor/s \& Fund project: Practical Handbook Of Creative Writing, Social Science Popularization and Application Research Project of Shandong Province, 2021, NO.2021-SKZZ-49.

\section{REFERENCES}

[1] Mei Zhen. The Discernment of Controversial Topics in Ecopoetics [J]. Journal of Poyang Lake, 2021(02):92101.
[2] Guo Xiaoyan. A Study on the Museum Culture Tradition of Western Eco-criticism[D]. Sichuan Academy of Social Sciences, 2020.

[3] Wang Shenglan. The typology and interpretation of the poetics of life[D]. Wuhan University,2018.

[4] Geng Xiaozhu. Nature, Ecology, and Politics [D]. Beijing Foreign Studies University, 2013.

[5] Li Haiyan. A comparative study of Wordsworth's poetics and Shelley's poetics [D]. Hunan Normal University, 2013.

[6] Huo Junming. The ethical ecology and "pathological" mechanism of literary criticism in the new century[J]. Art in a wide-angle, 2011(06):4-7.

[7] Liu Wenliang. Research on the Scope and Method of Eco-criticism [D]. Yangzhou University, 2007.

[8] Zhu Xinfu. Ecological Literature in the United States [D]. Soochow University, 2005. 